\title{
Diffractive multifocal intraocular lens interferes with intraoperative view
}

This article was published in the following Dove Press journal:

Clinical Ophthalmology

8 May 2010

Number of times this article has been viewed

\author{
Mami Yoshino' \\ Makoto Inoue ${ }^{1,2}$ \\ Nae Kitamura' \\ Hiroko Bissen-Miyajima' \\ 'Department of Ophthalmology, Tokyo \\ Dental College Suidobashi Hospital, \\ Tokyo, Japan; ${ }^{2}$ Kyorin Eye Center, \\ Kyorin University School of Medicine, \\ Tokyo, Japan
}

\begin{abstract}
We report an unusual finding during vitreous surgery in an eye implanted with a diffractive multifocal intraocular lens (IOL). A 70-year-old woman reported gradual visual deterioration to 20/40 in the left eye two and a half years after uneventful cataract surgery with implantation of a diffractive multifocal IOL. Funduscopic examination showed an epiretinal membrane (ERM) in the left eye. Increased macular traction was believed to cause the visual deterioration. Vitreous surgery with removal of the ERM was performed and triamcinolone acetonide (TA) was injected intravitreally to visualize the residual vitreous cortex. Although the ERM was peeled successfully, the ability to focus on the vitreoretinal interface through the IOL required great effort with decreased contrast sensitivity and ghost images of the intravitreal TA crystals. The vision improved to 20/25 4 months postoperatively. Macular surgery can be performed in an eye with a diffractive multifocal IOL; however, decreased contrast sensitivity and ghost images may interfere with the intraoperative view through the diffractive IOL in complicated cases.
\end{abstract}

Keywords: diffractive multifocal intraocular lens, intraoperative view

\section{Introduction}

The indications for newly developed multifocal intraocular lenses (IOLs) have expanded and their visual performance has been investigated. ${ }^{1}$ Despite favorable near and far visual results with diffractive multifocal IOLs, a symptomatic decrease in contrast sensitivity resulting from the optical design and precise observation of the retina and vitreous are concerns. We report the feasibility of macular surgery for epiretinal membranes (ERMs) and our experience with visualization during vitrectomy after implantation of a diffractive multifocal IOL.

\section{Case report}

A 70-year-old woman underwent uneventful bilateral cataract surgery with implantation of an aspheric diffractive multifocal IOL (ZM900 +21.0 diopters; Abbott Medical Optics) in the left eye on September 26, 2005, and (ZM900 +21.5 diopters; Abbott Medical Optics) in the right on October 3, 2005. The uncorrected distance visual acuity (VA) improved to 20/20 OD and 20/25 OS and the corrected distance VA also improved to $20 / 20$ OU 1 month postoperatively. Funduscopic examination was normal in both eyes.

The patient complained of vision that decreased in the left eye to 20/40 two and a half years after surgery; funduscopic examination showed an ERM in the left eye. Increased macular traction was believed to cause the visual deterioration. 
After informed consent was obtained, vitreous surgery was performed on February 21, 2008, with 25-gauge instruments and a conventional contact lens system. During the procedure, the surgeon noticed several unique findings through the diffractive multifocal IOL. To focus on the retinal vessels and macula, the surgeon needed to adjust the focus several times, especially when observing the premacular membrane, requiring great effort with decreased contrast sensitivity. However, the retinal folds resulting from contraction of the ERM were seen clearly and the ERM was peeled successfully (Figure 1A). The reflections off the intravitreal instruments changed and appeared as multiple wave-shaped arches (Figure 1B) or as one reflection off the instrument depending on the distance from the retina (Figure 1C). Observation of the peripheral retina and retinal vessels did not differ compared with a conventional monofocal IOL. When triamcinolone acetonide (TA) crystals were injected into the vitreous cavity to visualize the residual vitreous cortex, multiple or double crystals were observed; and the crystals were elongated radially in the peripheral field of the flat contact lens, although the crystals in the central field were not duplicated (Figure 1D). The crystals were more elongated radially in the peripheral view through the prism contact lens. Vision improved postoperatively to 20/25 4 months after the surgery with complete removal of ERM confirmed by optical coherence tomography (Figure 2).
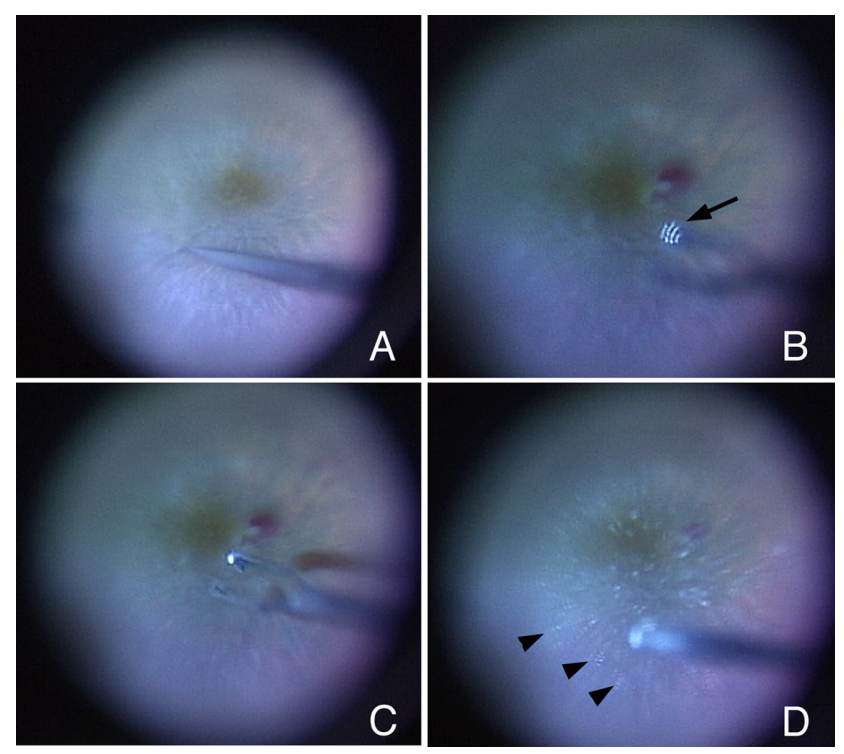

Figure I Intraoperative image through an operating microscope.

A) Retinal folds resulting from contraction of an epiretinal membrane are seen clearly. B) The reflection off an intravitreal instrument appears as multiple wave-shaped arches (arrow) or $\mathbf{C}$ ) as one reflection off the instrument depending on the distance from the retina. D) The crystals are elongated radially (arrowheads) in the peripheral field of the flat contact lens.

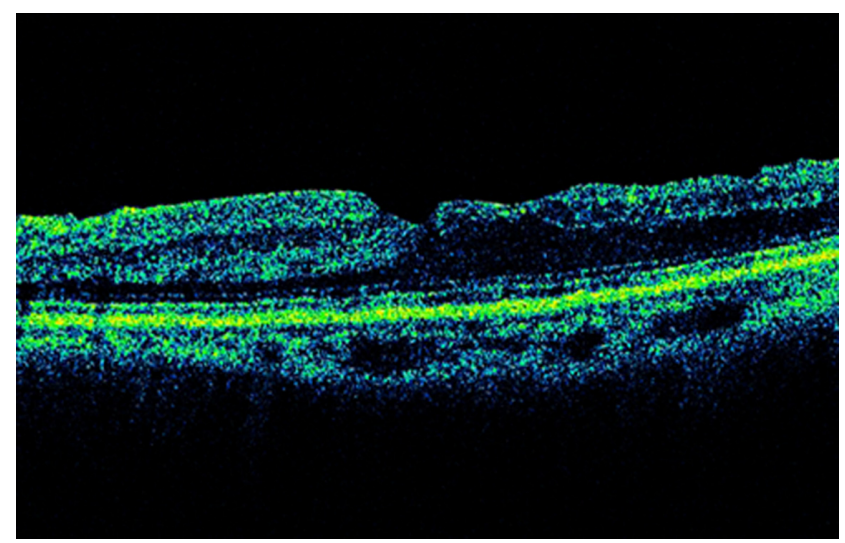

Figure 2 Postoperative image of optical coherence tomography (OCT). The OCT image indicates complete removal of epiretinal membrane 4 months after the surgery.

\section{Discussion}

The ZM900 has a diffractive design in addition to its aspheric optics to allow for sharply focused distant and near vision. ${ }^{1}$ Possible vitreoretinal complications have been discussed in eyes implanted with a multifocal IOL, although few clinical reports have been published except for those reporting difficulties during fluid-air exchange. ${ }^{2-4}$ We previously reported a case of retinal detachment that required vitreous surgery after implantation with a diffractive multifocal IOL. ${ }^{5}$ In the patient, intravitreal TA crystals disappeared at some depth in the vitreous cavity and then reappeared abruptly and were seen in duplicate. We were concerned about how diffractive multifocal IOLs affect visualization in macular surgery, which requires more precise visualization and delicate surgical procedures, including removal of ERMs.

We learned from the current case that macular surgery can be performed safely. However, the finding of decreased contrast sensitivity and ghost images, including multiple reflections of wave-shaped arches, may indicate how aberrations in the intraoperative view are affected by diffractive multifocal IOLs. The diffractive multifocal IOL may interfere with surgical procedures in complicated cases.

\section{Disclosures}

The authors do not have any financial support including any grants or funds in support of the study. The authors also do not have any financial and proprietary interest in any aspect of this report.

\section{References}

1. Terwee T, Weeber H, van der Mooren M, et al. Visualization of the retinal image in eye model with spherical and aspheric, diffractive, and refractive multifocal intraocular lenses. J Refract Surg. 2008;24:223-232. 
2. Charles S, Runge P. Vitreoretinal complications of multifocal intraocular lenses. In: Maxwell A, Nordan LT, eds. Multifocal Intraocular Lenses. Thorofare, NJ: Slack, Inc. 1991;209-218.

3. Kumar A, Goyal M, Tewari HK. Posterior segment visualization problems with multifocal intraocular lenses. Acta Ophthalmol Scand. 1996;74:415.
4. Lim JI, Kuppermann BD, Gwon A, et al. Vitreoretinal surgery through multifocal intraocular lenses compared with monofocal intraocular lenses in fluid-filled and air-filled rabbit eyes. Ophthalmology. 2000;107:1083-1088.

5. Kawamura R, Inoue M, Shinoda K, et al. Intraoperative findings during vitreous surgery after implantation of diffractive multifocal intraocular lens. J Cat Ref Surg. 2008;34:1048-1049.

\section{Publish your work in this journal}

Clinical Ophthalmology is an international, peer-reviewed journal covering all subspecialties within ophthalmology. Key topics include: Optometry; Visual science; Pharmacology and drug therapy in eye diseases; Basic Sciences; Primary and Secondary eye care; Patien Safety and Quality of Care Improvements. This journal is indexed on

Submit your manuscript here: http://www.dovepress.com/clinical-ophthalmology-journal

\section{Dovepress}

PubMed Central and CAS, and is the official journal of The Society of Clinical Ophthalmology (SCO). The manuscript management system is completely online and includes a very quick and fair peer-review system, which is all easy to use. Visit http://www.dovepress.com/ testimonials.php to read real quotes from published authors. 